\title{
Asthma and allergic rhinitis in Quebec children
}

\author{
Benoît Lévesque MD MSC FRCPC ${ }^{1}$, Marc Rhainds MD MSc FRCPC ${ }^{1}$, Pierre Ernst MD MSc FRCPC ${ }^{2}$, \\ Anne-Marie Grenier MD MSc FRCPC ${ }^{3}$, Tom Kosatsky MD MSc FRCPC ${ }^{4}$, Nathalie Audet MSc ${ }^{5}$, \\ Pierre Lajoie MD MPH FRCPC ${ }^{1}$
}

B Lévesque, M Rhainds, P Ernst, et al. Asthma and allergic rhinitis in Quebec children. Can Respir J 2004;11(5):343-348.

BACKGROUND: The Health and Social Survey of Quebec Children and Youth, conducted on representative samples of children nine, 13 and 16 years of age, provided data on the prevalence and determinants of asthma and allergic rhinitis in Quebec.

OBJECTIVES: To determine the prevalence of asthma and allergic rhinitis among children in the province of Quebec and to identify the determinants of these pathologies.

METHODS: Three groups of more than 1100 children aged nine, 13 and 16 years were recruited. Respiratory symptoms were documented using the International Study of Asthma and Allergies in Childhood questionnaire. Questions enquiring about family income, smoking, degree of urbanization of the child's school's location and various variables related to indoor air were also included. The comparisons of proportions were done using the $\chi^{2}$ test.

RESULTS: The prevalence rates for reported history of asthma varied from $14 \%$ to $15 \%$ depending on the age group. The prevalence of wheezing in the past year was $7 \%$ to $8 \%$. Asthma was the primary cause of the limitation of activities due to a health problem in nine- and 13-year-old Quebecers, and the second most common cause in 16-year-old Quebecers. The prevalence of rhinitis, rhinoconjunctivitis and reported history of hay fever increased with age, reaching $28.0 \%, 15.9 \%$ and $21.1 \%$, respectively, in the 16 -yearold group. The prevalence of asthma and wheezing was associated with family history and allergies, and inversely related to family income.

CONCLUSIONS: The prevalence of childhood asthma is high in the province of Quebec. It is a major cause of the limitation of activities due to a health problem for young Quebecers. A family history of asthma and an atopic predisposition are important determinants in the development of asthma in Quebec.

Key Words: Allergy; Asthma; ISAAC; Rhinitis

\section{Asthme et rhinite allergique chez les enfants du Québec}

HISTORIQUE : Aux fins l'Enquête sociale et de santé auprès des enfants et des adolescents québécois, les auteurs ont procédé à un échantillonnage représentatif d'enfants de 9,13 et 16 ans et ont recueilli et analysé des données sur la prévalence et les facteurs déterminants de l'asthme et de la rhinite allergique au Québec.

OBJECTIFS : Déterminer la prévalence de l'asthme et de la rhinite allergique chez les enfants du Québec et identifier les facteurs déterminants de ces pathologies.

MÉTHODES : Trois groupes de plus de 1100 enfants âgés de 9, 13 et 16 ans ont été formés. Les symptômes respiratoires ont été documentés à l'aide du questionnaire International Study of Asthma and Allergies in Childhood. D'autres questions, notamment sur le revenu familial, le tabagisme, le degré d'urbanisation, les établissements scolaires fréquentés par l'enfant et d'autres variables ayant trait à la qualité de l'air dans les maisons, ont aussi été posées. Les comparaisons de proportions ont été faites à l'aide du test du $\chi^{2}$.

RÉSULTATS : La prévalence des antécédents d'asthme recensés variait de 14 à $15 \%$ selon le groupe d'âge. La prévalence des sibilances au cours de l'année écoulée était de 7 à $8 \%$. L'asthme a été la principale cause de restriction des activités pour un problème de santé chez les jeunes québécois de 9 et de 13 ans et venait au deuxième rang chez les jeunes de 16 ans. La prévalence de la rhinite, de la rhinoconjonctivite et des antécédents de rhume des foins signalés a semblé augmenter avec l'âge, atteignant $28,0 \%, 15,9 \%$ et $21,1 \%$, respectivement, dans le groupe des jeunes de 16 ans. La prévalence de l'asthme et des sibilances a été associée à des antécédents familiaux et à des allergies et s'est révélée inversement proportionnelle au revenu familial.

CONCLUSION : La prévalence de l'asthme infantile est élevée au Québec. Elle est la principale cause des restriction des activités pour des problèmes de santé chez les jeunes québécois. Les antécédents familiaux d'asthme et la prédisposition d'origine atopique sont les principaux facteurs déterminants du développement de l'asthme au Québec.
$\mathrm{R}$ espiratory symptoms are common in childhood and are R responsible for much of the morbidity and school absenteeism in children under 16 years of age (1). Asthma is one of the most common chronic childhood illnesses in developed countries (2). In Montreal, the prevalence rate of asthma in three- and seven-year-old children increased from $3.8 \%$ in 1980 to $6.5 \%$ in 1983 (3). Also, Ernst et al (4) documented prevalence rates of $4.6 \%$ for asthma and $5.1 \%$ for wheezing in a population of five- to 13-year-old children in Montreal in 1992. Overall, despite some methodological difficulties, the number of childhood cases appears to be increasing in industrialized countries $(5,6)$.

Parallel with the growing prevalence of asthma, a higher number of consultations for hay fever has been noted, suggesting

${ }^{1}$ Direction régionale de santé publique de Quebec, Quebec City; ${ }^{2}$ Department of Medicine, McGill University, Montreal; ${ }^{3}$ Direction régionale de santé publique de la Mauricie et du Centre-du-Québec, Trois Rivières; ${ }^{4}$ Direction régionale de santé publique de Montreal-Centre, Montreal;

${ }^{5}$ Institut de la statistique du Québec, Montreal, Quebec

Correspondence: Dr Benoît Lévesque, Direction régionale de santé publique de Québec, 2400 D'Estimauville, Beauport, Quebec G1E 7G9.

Telephone 418-666-7000, fax 418-666-2776, benoit.levesque@inspq.qc.ca 
TABLE 1

\section{The English version of the International Study of Asthma} and Allergies in Childhood questionnaire

Asthma
1. Has your child ever had wheezing or whistling in the chest at
any time in the past?
2. Has your child had wheezing or whistling in the last 12
months? If you have answered NO please skip to
question 6 .
3. How many attacks of wheezing has your child had in the
last 12 months?
4. In the last 12 months, how often, on average, has your child's
sleep been disturbed due to wheezing?
Never woken with wheezing
Less than one night per week
One or more nights per week

5. In the last 12 months, has wheezing ever been severe enough to limit your child's speech to only one or two words at a time between breaths?

6. Has your child ever had asthma?

7. In the last 12 months, has your child's chest sounded wheezy during or after exercise?

8. In the last 12 months, has your child had a dry cough at night, apart from a cough associated with a cold or chest infection?

Yes $\square$

No $\square$

Yes $\square$

No $\square$

None $\square$

1 to $3 \square$

4 to $12 \square$

more than $12 \square$

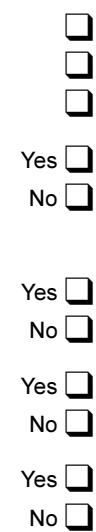

\section{Allergic rhinitis}

1. Has your child ever had a problem with sneezing or a runny or blocked nose when he/she did not have a cold or the flu? If you ansered no please skip to question 6 .

2. In the past 12 months, has your child had a problem with sneezing or a runny or blocked nose when he/she did not have a cold or the flu?

If you answered no please skip to question 6 .

3. In the past 12 months, was this nose problem accompanied by itchy-watery eyes?

4. In which of the past 12 months did this nose problem occur? (Please tick any that apply)

$\begin{array}{llllll}\text { January } & \square & \text { May } & \square & \text { September } & \square \\ \text { February } & \square & \text { June } & \square & \text { October } & \square \\ \text { March } & \square & \text { July } & \square & \text { November } & \square \\ \text { April } & \square & \text { August } & \square & \text { December } & \square\end{array}$

5. In the past 12 months, how much did this nose problem interfere with your child's daily activities:

6. Has your child ever had hay fever? that the secular changes in the morbidity of asthma may be secondary to the increasing numbers of atopic subjects (7). Atopy is intimately related to allergic manifestations such as rhinitis and is a recognized risk factor for recurrent episodes of wheezing (8) and bronchial hyper-reactivity (9). Therefore, atopy plays a major role in the incidence and severity of respiratory symptoms that characterize childhood asthma. Exposure to allergens in the ambient air, particularly antigens associated with mites, animal hair and cockroaches (10), is suspected of being an important determinant of asthma morbidity in the population.

In this regard, several authors have evaluated various indoor air parameters in relation to asthma. Second-hand smoke (11) or maternal smoking (12), the presence of animals or humidity problems (13) and the type of heating system (12) are some factors that have been implicated.

The Health and Social Survey of Quebec Children and Youth (HSSCY) was conducted on a sample designed to represent the province's population of nine-, 13- and 16-year-old children. One of the study's objectives was to describe the physical health of young people. The survey results related to the prevalence and determinants of asthma and allergic rhinitis are presented in the present study.

\section{METHODS}

HSSCY recruited through schools. In total, 189 schools were enrolled to make up three separate samples of approximately 1500 children nine, 13 and 16 years of age. The sample size was established to yield estimates with a coefficient of variation below 15\% for estimated proportions of $10 \%$ by sex and $7 \%$ with the sexes combined (14).

In total, 1267, 1186 and 1160 children nine, 13 and 16 years of age, respectively, participated in the study from eligible samples of 1520, 1498 and 1495, respectively, with participation rates of $83.4 \%, 79.2 \%$ and $77.6 \%$, respectively. The three samples were weighted to make them representative of all Quebec children of the same age (14). The data were collected in the fall of 1999.

The data on asthma and allergic rhinitis were collected by a self-administered questionnaire given to the parents with questions from the International Study of Asthma and Allergies in Childhood (ISAAC) questionnaire. This questionnaire was developed and validated in English, and then translated into several languages, including French (15) (Table 1). 'Wheezing in the last 12 months' and 'history of asthma' were considered a positive answer to questions 2 and 6, respectively, from the section of the questionnaire on asthma. A 'suspected asthmatic symptoms' index was developed; it was positive if either wheezing after exercise (question 7) or a nocturnal dry cough without a cold (question 8) was reported without wheezing in the past 12 months. Also, for respondents who had reported wheezing in the last 12 months (question 2), a severity index was created; 'severe wheezing' was considered to be present when changes in sleep (question 4) or speech (question 5) due to wheezing were reported.

Activity limitation due to asthma and its symptoms was examined to determine the impact of this health problem. This information was obtained from a separate section of the HSSCY questionnaire which was designed to detect limitation of daily living activities due to common health problems (food allergies; 
TABLE 2

Prevalence of asthma and wheezing

\begin{tabular}{clccccc}
\hline Group & & $\begin{array}{c}\text { History of } \\
\text { asthma } \\
(\%)\end{array}$ & $\begin{array}{c}\text { Wheezing* } \\
(\%)\end{array}$ & $\begin{array}{c}\text { Severe } \\
\text { whezing } \\
(\%)\end{array}$ & $\begin{array}{c}\text { Suspected } \\
\text { asthmatic } \\
\text { symptoms } \\
(\%)\end{array}$ & $\begin{array}{c}\text { Family } \\
\text { history of } \\
\text { asthma } \\
(\%)\end{array}$ \\
\hline $\mathbf{9}$ years & Boys & 18.0 & $8.8^{\dagger}$ & $5.2^{\dagger}$ & 11.4 & 15.2 \\
of age & Girls & 11.2 & $5.5^{\dagger}$ & $3.5^{\ddagger}$ & $7.5^{\dagger}$ & 18.1 \\
& P§ & 0.007 & 0.07 & 0.24 & 0.05 & 0.49 \\
& Total & 14.7 & 7.2 & $4.4^{\dagger}$ & 9.4 & 16.6 \\
$\mathbf{1 3}$ years & Boys & 14.5 & $7.3^{\dagger}$ & $2.9^{\ddagger}$ & $8.7^{\dagger}$ & 16.0 \\
of age & Girls & 16.0 & $8.4^{\dagger}$ & $1.9^{\ddagger}$ & $9.9^{\dagger}$ & 16.0 \\
& P§ & 0.55 & 0.55 & 0.34 & 0.58 & 0.95 \\
& Total & 15.2 & 7.8 & $2.4^{\dagger}$ & 9.3 & 16.0 \\
$\mathbf{1 6}$ years & Boys & 13.8 & $6.8^{\dagger}$ & $3.4^{\dagger}$ & $9.8^{\dagger}$ & 15.2 \\
of age & Girls & 14.4 & $9.6^{\dagger}$ & $3.7^{\dagger}$ & 14.6 & 15.2 \\
& P§ & 0.80 & 0.15 & 0.86 & 0.04 & 0.62 \\
& Total & 14.1 & 8.2 & $3.5^{\dagger}$ & 12.2 & 15.2 \\
& Pा & 0.80 & 0.72 & 0.10 & 0.10 & 0.69 \\
\hline
\end{tabular}

${ }^{*}$ For the past twelve months; ${ }^{+}$Coefficient of variation between $15 \%$ and $25 \%$ - interpret with care; ${ }^{\ddagger}$ Coefficient of variation above $25 \%$ - imprecise estimate; §Comparison by sex; ${ }^{\top}$ Comparison by age group

asthma; respiratory problems other than asthma; skin problems; emotional, psychological or nervous problems; bone or joint problems; cystic fibrosis; intestinal problems; thyroid, liver and kidney problems or disease; diabetes; cholesterol or lipid problems; or other chronic health problems). 'Family history of asthma' and 'family history of hay fever' were also obtained from another section of the HSSCY. For both outcomes, it was considered positive if one parent suffered from asthma or hay fever, respectively. 'Rhinitis in the last 12 months', 'rhinoconjunctivitis in the last 12 months' and 'history of hay fever' were determined by answers to questions 1, 2 and 6, respectively, from the section of the questionnaire on rhinitis (Table 1). Rhinitis symptom severity was defined on the basis of interference with daily activities (question 5) (Table 1).

To assess the importance of atopy and heredity in the prevalence of asthma and its symptoms, reported history of asthma and wheezing were examined in relation to reported history of hay fever, symptoms of rhinitis, allergies other than hay fever, as well as a family history of asthma. For 13- and 16-year-old participants, the prevalence rates for wheezing and reported history of asthma were examined in relation to smoking status and stratified into two categories: smokers, defined as a person who smoked at least 100 cigarettes in their life and who smoked during the last 30 days preceding the survey; and nonsmokers. Wheezing and reported history of asthma were also examined in relation to family income, urbanization of the attended school location (in two categories: fewer than 50,000 inhabitants and 50,000 inhabitants or more), as well as to various variables related to indoor air, namely, passive smoking, home occupancy (based on the ratio of the number of people to the number of rooms), heating system, ventilation, and rugs and animals in the home. Furthermore, a specific question asked families to document the modifications to their home due to respiratory problems in one or more residents since the first year of living in their dwelling. Most questions relating to indoor air were adapted from tools developed and used
TABLE 3

Prevalence of hay fever and rhinitis

\begin{tabular}{|c|c|c|c|c|c|}
\hline Group & & $\begin{array}{c}\text { History of } \\
\text { hay fever } \\
(\%)\end{array}$ & $\begin{array}{l}\text { Rhinitis* } \\
\text { (\%) }\end{array}$ & $\begin{array}{c}\text { Rhino- } \\
\text { conjunctivitis* } \\
(\%)\end{array}$ & $\begin{array}{c}\text { Family } \\
\text { history of } \\
\text { hay fever } \\
(\%)\end{array}$ \\
\hline 9 years & Boys & $9.7^{\dagger}$ & 19.2 & $6.2^{\dagger}$ & 30.9 \\
\hline \multirow[t]{3}{*}{ of age } & Girls & $9.8^{\dagger}$ & 14.4 & $6.0^{\dagger}$ & 30.5 \\
\hline & $\mathrm{P}^{\ddagger}$ & 0.96 & 0.07 & 0.23 & 0.82 \\
\hline & Total & 9.7 & 16.9 & 6.1 & 30.7 \\
\hline 13 years & Boys & 17.6 & 26.6 & 12.3 & 28.5 \\
\hline \multirow[t]{3}{*}{ of age } & Girls & 12.9 & 21.3 & 10.4 & 30.0 \\
\hline & $\mathrm{P}^{\ddagger}$ & 0.07 & 0.08 & 0.73 & 0.89 \\
\hline & Total & 15.3 & 24.0 & 11.4 & 29.2 \\
\hline 16 years & Boys & 21.8 & 29.6 & 15.5 & 23.0 \\
\hline \multirow[t]{4}{*}{ of age } & Girls & 20.4 & 26.5 & 16.3 & 27.8 \\
\hline & $\mathrm{P}^{\ddagger}$ & 0.60 & 0.32 & 0.20 & 0.23 \\
\hline & Total & 21.1 & 28.0 & 15.9 & 25.5 \\
\hline & $\mathrm{P} \S$ & $\leq 0.001$ & $\leq 0.001$ & $\leq 0.001$ & $\leq 0.001$ \\
\hline
\end{tabular}

${ }^{*}$ For the last 12 months; ' ${ }^{+}$Coefficient of variation between $15 \%$ and $25 \%$ interpret with care; ${ }^{\ddagger}$ Comparison by sex; $\S^{\circledR}$ Comparison by age group

on large samples in the context of the European Community Respiratory Health Survey (16) and the study of the respiratory health of Montreal youth (4).

Statistical comparisons of the proportions from the weighted populations were done using $\chi^{2}$ tests. Due to variations in the weighting, the number of respondents was not indicated in the results tables. However, for all of the questions used, partial nonresponse was always below $5 \%$. Furthermore, due to the low prevalence of certain variables, the coefficients of variation associated with some of the estimates were sometimes above 15\% and even $25 \%$, indicating reduced precision. Such reduced precision was noted in the results tables.

\section{RESULTS}

Table 2 describes the prevalence of asthma and wheezing stratified by age and sex. First, prevalence rates of $14 \%$ to $15 \%$ for reported history of asthma were noted in the three age groups. Such individual cumulative prevalence rates were of the same order of magnitude than that observed for both parents combined. The proportion of children and adolescents suffering from wheezing in the past 12 months was $7 \%$ to $8 \%$, while those suffering from severe wheezing, indicating poorly controlled asthma, varied from $2.4 \%$ to $4.4 \%$, depending on the age group. Again, depending on the age group, the proportions of suspected asthmatic symptoms ranged from $9.3 \%$ (13-year-old group) to $12.2 \%$ (16-year-old group).

For all of the outcomes, there were no significant differences among age groups. However, in the youngest group (nine years of age), a higher prevalence of reported history of asthma and suspected asthmatic symptoms was noted in boys. Conversely, in the 16-year-old group, the prevalence of suspected asthmatic symptoms was higher in girls.

Table 3 presents the proportions of young people with history of hay fever, and symptoms of rhinitis and rhinoconjunctivitis in 
TABLE 4

Modifications to homes due to respiratory problems in one or more residents since the first year of living in the dwelling

\begin{tabular}{|c|c|c|c|c|c|c|}
\hline Group & $\begin{array}{l}\text { Removed } \\
\text { rugs* (\%) }\end{array}$ & $\begin{array}{c}\text { Increased } \\
\text { ventilation (\%) }\end{array}$ & $\begin{array}{c}\text { Reduced } \\
\text { tobacco (\%) }\end{array}$ & $\begin{array}{c}\text { Eliminated } \\
\text { animals }^{\dagger}(\%)\end{array}$ & $\begin{array}{c}\text { Controlled } \\
\text { mites (\%) }\end{array}$ & $\begin{array}{c}\text { One } \\
\text { modification (\%) }\end{array}$ \\
\hline 9 years of age & 17.7 & 16.5 & 20.5 & 9.2 & 18.8 & 42.7 \\
\hline 16 years of age & 20.4 & 19.1 & 19.5 & 11.0 & 18.0 & 45.9 \\
\hline
\end{tabular}

${ }^{*}$ Proportion of those who already had rugs in this home; tProportion of those who already had animals in this home

\section{TABLE 5}

Exposure to risk factors likely to change the air quality in the homes of children and adolescents who report asthma or wheezing

\begin{tabular}{clcc}
\hline Group & Risk factor & History of asthma (\%) & Wheezing* $\mathbf{~}^{*}$ ) \\
\hline 9 years & Passive smoking & 46.6 & 50.8 \\
of age & Rugs & 32.4 & $37.2^{\dagger}$ \\
& Animal: cat & $24.0^{\dagger}$ & $22.3^{\dagger}$ \\
& Animal: dog & $29.6^{\dagger}$ & $28.0^{\dagger}$ \\
13 years & Passive smoking & 49.1 & $43.0^{\dagger}$ \\
of age & Rugs & 32.9 & $29.8^{\dagger}$ \\
& Animal: cat & 34.6 & $33.7^{\dagger}$ \\
& Animal: dog & 40.8 & $38.0^{\dagger}$ \\
16 years & Passive smoking & 47.5 & $52.1^{\prime}$ \\
of age & Rugs & 35.4 & $37.0^{\dagger}$ \\
& Animal: cat & 29.3 & $22.8^{\dagger}$ \\
& Animal: dog & 39.9 & $39.3^{\dagger}$ \\
\hline
\end{tabular}

"For the last 12 months; ${ }^{\dagger}$ Coefficient of variation between $15 \%$ and $25 \%$ interpret with care

the past 12 months. There were no significant differences between boys and girls. However, for each of the three clinical entities, the prevalences clearly increased with age $(\mathrm{P} \leq 0.001)$. Between 25.5\% (16-year-old group) and $30.7 \%$ (nine-year-old group) of the young people participating in the present study had a family history of hay fever, another indication of the high frequency of this pathology in the population.

Few young people were identified as being limited in their activities due to a chronic illness or a health problem (nine years of age: $1.8 \% ; 13$ years of age: $7 \%$; and 16 years of age: $8.0 \%$ ). However, for those who were limited in their activities, asthma was the principal reason in approximately one-half of the nine-year-old (51\%) and 13-year-old (45\%) groups, as well as in one-quarter of the 16-year-old group (26\%). Asthma was the principal cause of limitation in daily activities in the nine- and 13-year-old groups, and the second most common cause in the 16-year-old group, after osteoarticular problems $(37 \%)$.

Furthermore, $11.4 \%, 7.0 \%$ and $6.8 \%$ of the parents of the nine-, 13- and 16-year-old rhinitis sufferers, respectively, estimated that the symptoms that affected their children interfered moderately or greatly with their daily activities. These numbers indicated that despite its benign character, rhinitis, in its most severe form, may significantly affect the quality of life of young people.
The associations between the prevalence rates for wheezing and reported history of asthma and the prevalence rates for reported history of hay fever, rhinitis and allergies other than hay fever were examined. They were all highly significant $(\mathrm{P} \leq 0.001)$, indicating that asthma in children and adolescents in Quebec was associated with the presence of allergies, and as such, with a presumed atopic state. The important genetic component of childhood asthma in Quebec is also illustrated by the fact that, regardless of age group, the prevalence of wheezing and reported history of asthma was strongly associated $(\mathrm{P} \leq 0.001)$ with a family history of asthma.

No relationship between smoking and the prevalence of asthma or wheezing in 13- and 16-year-old adolescents was found. The same was true for the three age groups in relation to the presence of tobacco smoke in the home and the degree of urbanization of the school location. However, history of asthma in young people 16 years of age $(\mathrm{P}=0.02)$ and nine years of age $(\mathrm{P}=0.01)$, as well as wheezing in the latter age group $(\mathrm{P}=0.005)$, increased in prevalence in relation to lower family income.

As with passive smoking, no variable associated with indoor air quality, namely, home occupancy, type of heating system, ventilation, or even animals or rugs in the home, was significantly associated with reported history of asthma or with wheezing. However, more than $40 \%$ of the parents of the young people who participated in the survey made changes to their homes because someone in their household suffered from asthma, allergies or other respiratory problems (Table 4). These changes were examined in relation to the prevalence of wheezing and reported history of asthma. These two variables were significantly related $(\mathrm{P} \leq 0.001)$ to the implementation of one of the suggested environmental control measures, indicating more frequent changes in the homes of subjects with asthma or wheezing. However, as shown in Table 5, the presence of rugs $(30 \%$ to $40 \%)$ and animals $(20 \%$ to $40 \%)$, and passive smoking ( $40 \%$ to $50 \%$ ), remained highly prevalent risk factors in the homes of young people suffering from wheezing, or who have suffered or are still suffering from asthma.

\section{DISCUSSION}

In the present study, information was obtained on the prevalence of asthma and allergic rhinitis in Quebec. The questionnaire used was developed within the framework of the ISAAC protocol and has been administered to thousands of children worldwide (17-19). Our results indicate that between $14 \%$ to $15 \%$ of Quebec youth nine, 13 and 16 years of age had already had or still had asthma. In the Montreal region, $12.1 \%$ of children 
five to 13 years of age had had or still had asthma (4), and prevalence rates of $17.2 \%$ and $11.2 \%$ for children six and seven years of age, and $19.2 \%$ and $12.2 \%$ for those 13 and 14 years of age were documented in Hamilton and Saskatoon, respectively (20). Our results on the prevalence of family history of asthma was almost similar to the prevalence of individual history of asthma in children. The family history of asthma was based on data for both parents combined. Therefore, we can presume that the individual prevalence for history of asthma in children was probably approximately twice as high as the reported prevalence among individual parents, suggesting an increase in the prevalence of the disease between generations.

For wheezing during the past year, the proportions in the current study varied from $7.2 \%$ to $8.2 \%$ for the three age groups. They are, therefore, slightly higher than the $5.1 \%$ documented by Ernst et al (4) in 1992 for Montreal youth. However, they are clearly lower than those documented by Habbick et al (20), namely, $20.1 \%$ and $14.1 \%$ for six- and sevenyear-old children and $30.6 \%$ and $24.0 \%$ for 13 - and 14 -yearold adolescents in Hamilton and Saskatoon, respectively. This contrasts with the similar prevalence rates of past or current asthma in these different studies. Internationally, in the 13- to 14-year-old age group, 155 centres (463,801 children) from 56 countries that participated in the ISAAC study $(18,19)$ reported a wide range of prevalence rates of wheezing in the past 12 months (2.1\% to $32.2 \%$ ). Prevalence rates under $10 \%$ were reported mainly in Asia, Northern Africa, Eastern Europe and the eastern Mediterranean regions. By contrast, prevalences were generally over $20 \%$ in the United Kingdom, Australasia, North America and Latin America (19). The report of wheezing in the past 12 months was generally more common than the report of 'history of asthma' (19).

It is likely that the difficulties in translating the term wheezing into French may explain the lower prevalence of wheezing in Quebec. Osterman et al (21) had previously highlighted a difference between French and English workers in the Montreal region in the prevalence of reported wheezing, which appeared to be explained by language differences. Wheezing was reported significantly less frequently by the French speaking participants. Furthermore, in the ISAAC survey $(18,19)$, higher prevalence rates of wheezing were found in English-speaking countries. In the current study, approximately $85 \%$ of the respondents answered the French questionnaire. In the nine-year-old group, the prevalence of wheezing was twice as high in anglophones as in francophones (14\% versus $6 \%$, $\mathrm{P}=0.01$ ). However, for the 13- and 16-year-old groups, the prevalence rates of francophones and anglophones were essentially the same. Therefore, the cultural factor alone does not seem to explain the differences noted. In the present study, the parents answered the questionnaires, regardless of the age group, while in the Hamilton and Saskatoon study (20), the 13- and 16-year-old participants answered the questionnaire themselves. This is another factor that may explain the differences observed.

Concerning the impact of asthma as a health problem for children, our survey data highlighted the fact that asthma was the primary cause of the limitation of activities of daily living due to a health problem in nine- and 13-year-old Quebecers, and the second most common cause among 16-year-old Quebecers.

The ISAAC survey (17) of 463,801 young people 13 and 14 years of age reported 25 th percentiles of $21.2 \%$ and $9.0 \%$ and 50 th percentiles of $30.3 \%$ and $13.6 \%$ of the average prevalence rates of rhinitis and rhinoconjunctivitis, respectively, in the 155 participating centres from the 56 countries. The present study demonstrated results of $24 \%$ for rhinitis and $11.5 \%$ for rhinoconjunctivitis in 13-year-old adolescents, falling between the 25th and 50th percentiles documented in ISAAC.

Our results confirm the importance of genetic factors, illustrated by the importance of family history, and an atopic predisposition (rhinitis) in the development of asthma and wheezing. Other than an inverse relationship with household income, the present study did not identify associations between asthma or wheezing and environmental factors. A possible explanation may be the changes made to the risk factors by the families of the young people with respiratory problems, which may have masked these relationships. Nevertheless, environmental risk factors were still present in a notable proportion of households of young asthma and wheezing sufferers. The rather crude assessment of the environment and the cross-sectional design of our study may also have led to an underestimation of the role of the environment.

ACKNOWLEDGEMENTS: The authors wish to thank the people in charge and the personnel of Health and Social Survey of Quebec Children and Youth for their collaboration, particularly Claudette Lavallée and Jacinthe Aubin. The authors also thank Lise Coté, Lina Bergeron and Helen Shaver for their contribution to this study.

\section{REFERENCES}

1. Ransom MR, Pope CA 3rd. Elementary school absences and PM10 pollution in Utah Valley. Environ Res 1992;58:204-19.

2. Mielck A, Reitmer P, Wjst M. Severity of childhood asthma by socioeconomic status. Int J Epidemiol 1996;25:388-93.

3. Infante-Rivard C, Esnaola Sukia S, Roberge D, Baumgarten M. The changing frequency of childhood asthma. J Asthma 1987;24:283-8

4. Ernst P, Demissie K, Joseph L, Locher U, Becklake MR. Socioeconomic status and indicators of asthma in children. Am J Respir Crit Care 1995;152:570-5.

5. Burney PG, Chinn S, Rona RJ. Has the prevalence of asthma increased in children? Evidence from the national study of health and growth 1973-86. Brit Med J 1990;300:1306-10.

6. Weiss KB, Gergen PJ, Wagener DK. Breathing better or wheezing worse? The changing epidemiology of asthma morbidity and mortality. Annu Rev Public Health 1993;14:491-513.

7. Newman-Taylor A. Environmental determinants of asthma. Lancet 1995;345:296-9.

8. Sibbald B, Horn ME, Brain EA, Gregg I. Genetic factors in childhood asthma. Thorax 1980;35:671-4.

9. Cookson WO, Musk AW, Ryan G. Association between asthma history, atopy, and non-specific bronchial responsiveness in young adults. Clin Allergy 1986;16:425-32.

10. Platts-Mills TAE, Carter MC. Asthma and indoor exposures to allergens. N Engl J Med 1997;336:1382-4.

11. Maier WC, Arrighi HM, Morray B, Llewellyn C, Redding GJ. Indoor risk factors for asthma and wheezing among Seattle school children. Environ Health Perspect 1997;105:208-14. 
12. Infante-Rivard C. Childhood asthma and indoor environmental risk factors. Am J Epidemiol 1993;137:834-44.

13. Daigler GE, Markello SJ, Cummings KM. The effects of indoor air pollutants on otitis media and asthma in children. Laryngoscope 1991;101:293-6.

14. Institut de la statistique du Québec. Enquête sociale et de santé auprès des enfants et des adolescents québécois 1999. Québec: Publications du Québec, 2002:519.

15. Jenkins MA, Clarke JR, Carlin JB, et al. Validation of questionnaire and bronchial hyperresponsiveness against respiratory physician assessment in the diagnosis of asthma. Int J Epidemiol 1996;25:609-16.

16. Burney PG, Luczynska C, Chinn S, Jarvis D. The European Community Respiratory Health Survey. Eur Respir J 1994;7:954-60.

17. Strachan D, Sibbald B, Weiland S, et al. Worldwide variations in prevalence of symptoms of allergic rhinoconjunctivitis in children:
The International Study of Asthma and Allergies in Childhood (ISAAC). Pediatr Allergy Immunol 1997;8:161-76.

18. International Study of Asthma and Allergies in Childhood (ISAAC) Steering Committee. Worldwide variation in prevalence of symptoms of asthma, allergic rhinoconjunctivitis, and atopic eczema: ISAAC. Lancet 1998;351:1225-31.

19. Asher MI, Weiland SK, on behalf of the ISAAC Steering Committee. The International Study of Asthma and Allergies in Childhood (ISAAC). Clin Exp Allergy 1998;28(Suppl 5):52-66,90-1

20. Habbick BF, Pizzichini MM, Taylor B, Rennie D, Senthilselvan A, Sears MR. Prevalence of asthma, rhinitis and eczema among children in 2 Canadian cities: The International Study of Asthma and Allergies in Childhood. CMAJ 1999;160:1824-8.

21. Osterman JW, Armstrong BG, Ledoux E, Sloan M, Ernst P. Comparison of French and English versions of the American Thoracic Society respiratory questionnaire in a bilingual working population. Int J Epidemiol 1991;20:138-43. 


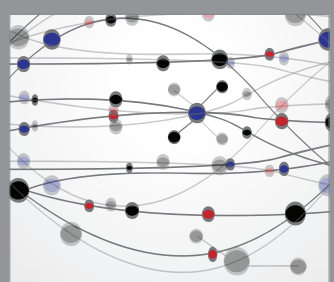

The Scientific World Journal
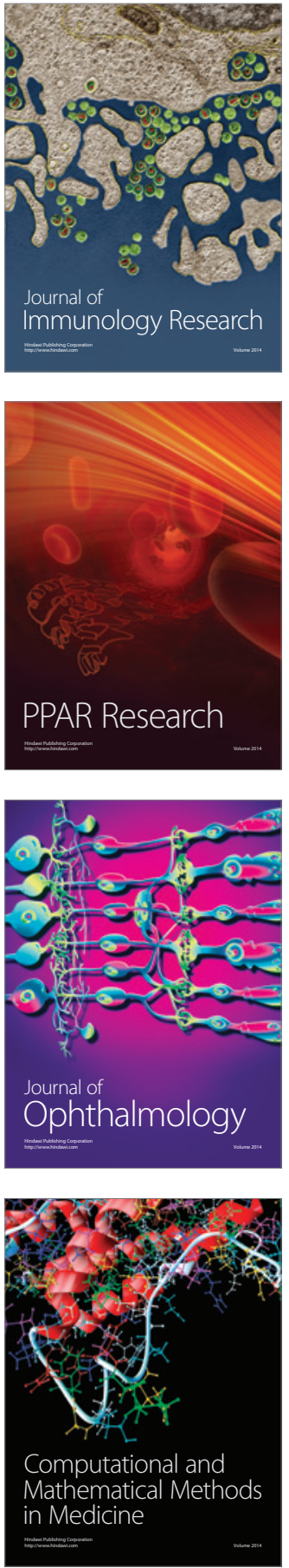

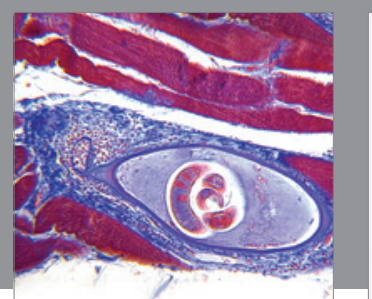

Gastroenterology Research and Practice

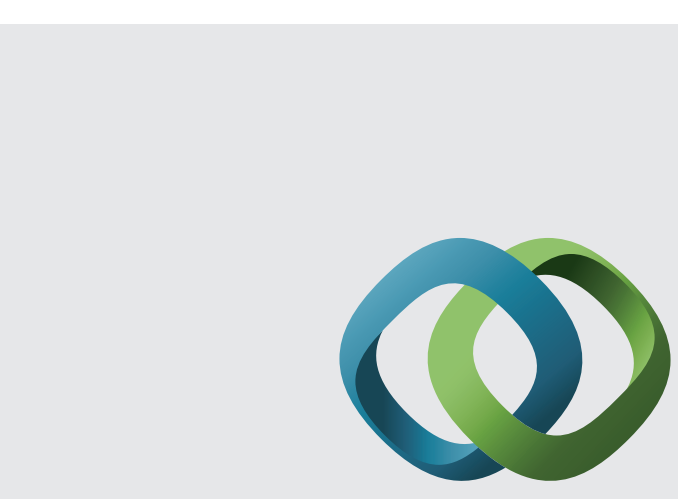

\section{Hindawi}

Submit your manuscripts at

http://www.hindawi.com
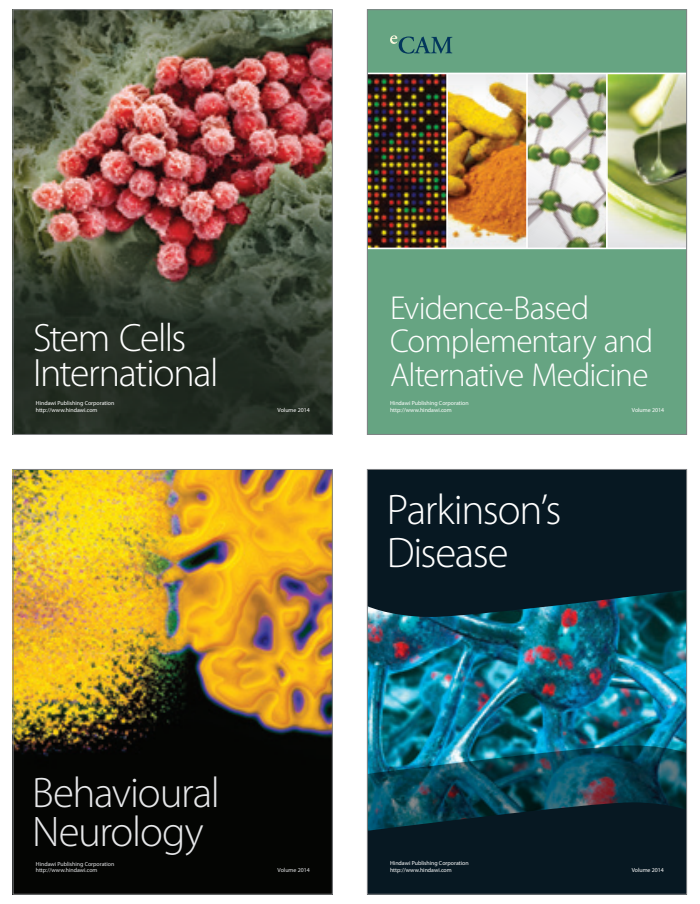
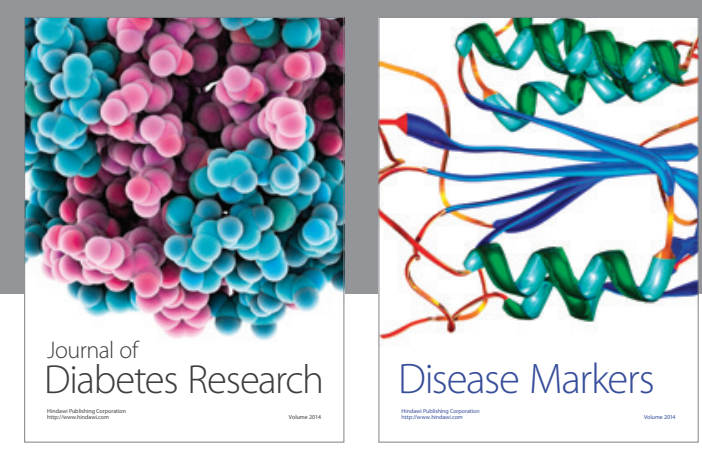

Disease Markers
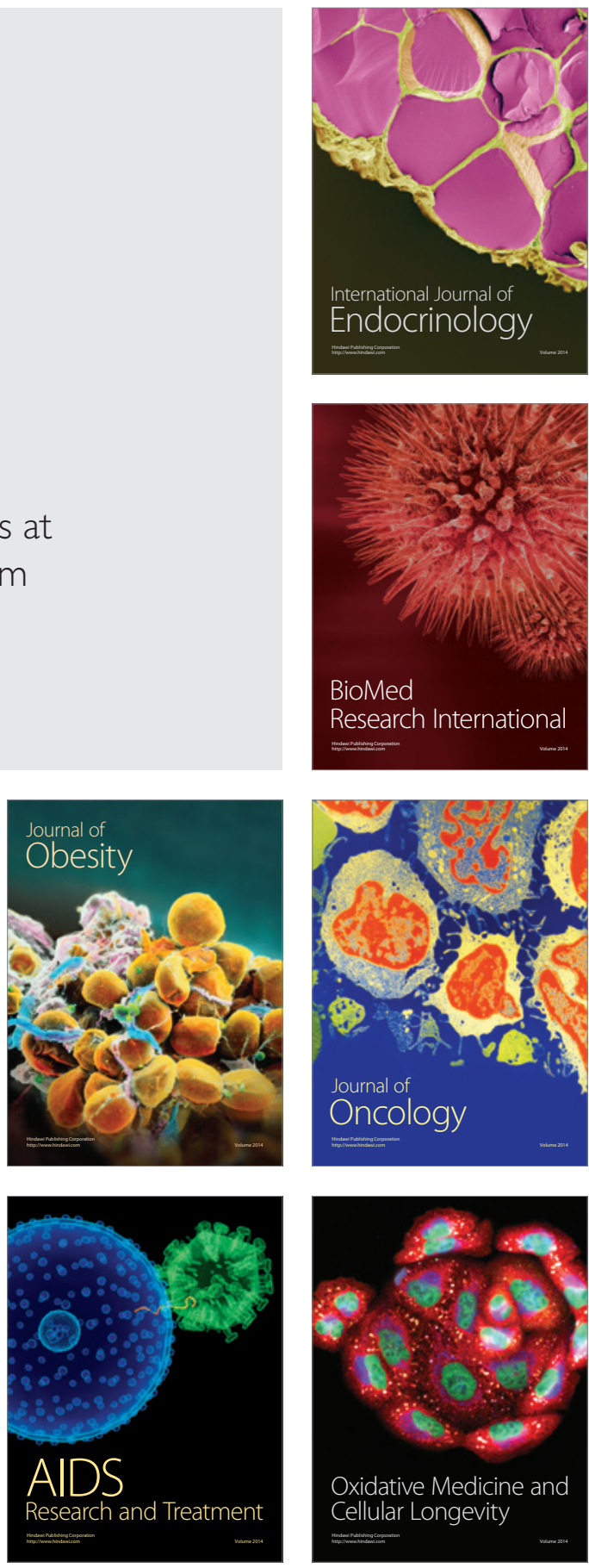